\title{
PRÁTICAS PEDAgógICAS DE PROFESSORES DO CAMPO: UM ESTUDO DE CASO ETNOGRÁFICO
}

\author{
PEDAGOGICAL PRACTICES OF THE FIELD TEACHERS: AN ETHNOGRAPHIC \\ CASE STUDY
}

Maria Lemos da Costa ${ }^{1}$

\begin{abstract}
RESUMO: Este trabalho traz para reflexão as contribuições do estudo de caso etnográfico sobre as práticas pedagógicas de professores que atuam na Educação do Campo. Tivemos como questão norteadora: como a perspectiva metodológica do estudo de caso etnográfico contribui para compreendermos as práticas pedagógicas dos professores da Educação do Campo? Esta pesquisa foi realizada com dez professores em uma Escola Família Agrícola do Piauí que desenvolve um ensino com a Pedagogia da Alternância. A análise se subsidia nos estudos de: André (2008), Arroyo (2012), Angrosino (2009), Franco (2016), Gimonet (2007) Jesus (2011) Matos (2011), Arroyo, Caldart e Molina (2009), Rocha (2010), dentre outros que deram embasamento para as discussões teórico e metodológico. Para a construção dos dados, tivemos como instrumentos, a observação participante e a produção de diário de formação, os quais possibilitaram fazer uma análise descritiva e interpretativa das práticas pedagógicas desenvolvidas na Educação do Campo, bem como dos saberes que possibilitam respeitar a cultura dos camponeses. Os resultados da pesquisa evidenciaram a importância dessa metodologia de pesquisa para realizarmos um estudo a partir do cotidiano da prática, evidenciando-a como espaço de construção de saberes, trazendo contribuições para um ensino pautado nas vivências e na cultura dos camponeses, o que implica em uma pedagogia que valoriza os aspectos socioculturais locais, aspectos contemplados na Pedagogia da Alternância.
\end{abstract}

Palavras-chave: Etnografia. Práticas Pedagógicas. Pedagogia da Alternância.

ABSTRACT: This paper reflects on the contributions of the ethnographic case study about the pedagogical practices of field teachers. It is based on a guiding question: how does the methodological perspective of the ethnographic case study help to understand the teachers' pedagogical practices in the field Education? This research was done with ten teachers in an Agricultural Family School of Piauí. This school develops an alternation pedagogy teaching method. The analysis is supported in the studies of: André (2008), Arroyo (2012), Angrosino (2009), Franco (2016), Gimonet (2007), Jesus (2011), Matos (2011), Arroyo, Caldart and Molina Rocha (2010), and others authors. As instruments to data collecting it was used the participant observation and the formation diary production, which helped to make a descriptive and interpretative analysis of pedagogical practices developed in the Education of the Field, as well as the knowledge that make possible to respect the local community culture. The research results evidenced the importance of this methodology to carry out a study based on the daily practice, emphasizing it as a space for the construction of knowledge. So, it brings

\footnotetext{
${ }^{1}$ Mestre e Doutora em Educação, Professora adjunta da Universidade Federal do Piauí do Centro de Ciências da Educação. do Departamento de Métodos e Técnicas - UFPI/CCE/DMTE de Teresina - Piauí - Brasil. Email marialc08@yahoo.com.br.
}

Revista Ibero-Americana de Humanidades, Ciências e Educação. Criciúma, v.5. n.3, 2019. 


\section{Universidade do Extremo Sul Catarinense \\ Revista Ibero-Americana de Humanidades, Ciências e \\ Educação \\ UnesC Produção e democratização do conhecimento na lbero-América}

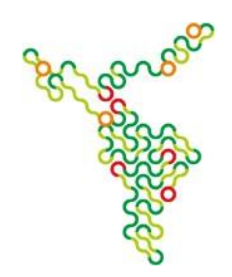

contributions to an education based on the experiences and the dwellers' way of life, which implies a pedagogy that takes into account the local sociocultural aspects, which is included in the Alternation Pedagogy.

Key words: Ethnography. Pedagogical practices. Pedagogy of the Alternation

\section{Introdução}

Este artigo apresenta os resultados de uma pesquisa na modalidade da pesquisa etnográfica com um estudo de caso etnográfico, focando a prática pedagógica desenvolvida por professores em uma escola do campo. Realizada com dez professores em Escola Família Agrícola - EFA Soinho, localizada na zona rural do município de Teresina - Piauí - Brasil. Neste trabalho discorremos sobre as contribuições do estudo de caso etnográfico, como opção metodológica para as pesquisas em educação, destacando a sua importância para compreendermos as práticas pedagógicas na Educação do Campo.

Partimos da seguinte questão norteadora: Quais as contribuições do estudo de caso etnográfico na pesquisa para compreendermos as práticas pedagógicas de professores da Educação do Campo? Trazendo como objetivo geral: analisar as contribuições do estudo de caso etnográfico para compreendermos as práticas pedagógicas de professores da Educação do Campo; específicos: discutir as perspectivas teóricas e metodológicas do estudo de caso etnográfico e identificar as contribuições dessa metodologia para a análise descritiva e interpretativa das práticas pedagógicas. Assim, produzirmos conhecimento que possibilite relacionar os estudos etnográficos com as práticas pedagógicas, trazendo à importância para as pesquisas em educação.

Com o estudo de caso etnográfico foi possível perceber elementos do cotidiano dos professores da Educação do Campo no desenvolvimento de suas práticas pedagógicas. O que revelou saberes, modos de vida, cultura escolar, metodologias diversificadas que promovem o encontro entre saber popular, saber escolar e saber cientifico numa relação dialógica entre a escola e a comunidade. Assim, anunciando as especificidades da Educação do Campo para promoção de ensino pautado no protagonismo dos camponeses, no fortalecimento da sua cultura, dos valores e princípios que os identificam como sujeitos de direitos. 


\section{Universidade do Extremo Sul Catarinense \\ Revista lbero-Americana de Humanidades, Ciências e \\ Educação \\ Unesc Produção e democratização do conhecimento na lbero-América}

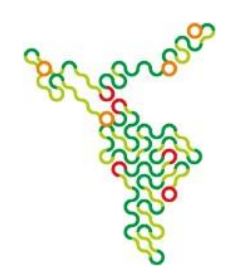

\section{Perspectivas teóricas e metodológicas do estudo de caso etnográfico}

Dedicar tempo para realizar uma pesquisa significa a busca pelo conhecimento, pela aprendizagem, pela sabedoria, pela descoberta, pelo novo, para conceber novas formas de ver e de pensar a sociedade em suas relações sociais e históricas. Para uma interpretação aprofundada e criteriosa da realidade pesquisada, a metodologia se constitui de suma importância.

Ao optarmos pelo estudo de caso etnográfico, entendemos que tudo parece ter sentido: os gestos, as palavras, as imagens, que possibilitam rememorar o passado, os diálogos e tantos outros meios, com os quais podem interagir pesquisador e pesquisados. Essa interação resultou na percepção das práticas pedagógicas dos professores da Educação do campo e, a partir da observação de tais práticas, foi possível descrever, analisar e compreender as suas nuances dentro de um contexto.

Para André (2008), o estudo de caso possui relevância na produção do conhecimento, pois tem base nas vivências, nas relações contextuais dos sujeitos, possibilitando ao pesquisador fazer desde a descrição densa de um fenômeno à compreensão do mesmo em suas múltiplas relações. Vale ressaltar a relação do estudo de caso etnográfico com a perspectiva da etnografia, no sentido de dar voz aos sujeitos, da inclusão do pesquisador na vida social e cultural dos sujeitos pesquisados. Traz possibilidades de se assimilar, interpretar, descrever e fazer uma análise holística da cultura, compreendida como “[...] um sistema de significados mediadores entre as estruturas sociais e as ações e interações humanas" (MATOS, 2011, p. 50).

Partindo desses pressupostos, realizamos uma análise descritiva, interpretativa e crítica dos conteúdos imitidos pelos partícipes e observados na estadia no campo de pesquisa, em suas várias relações com o objeto de estudo. A partir da base teórica epistemológica desta pesquisa, buscamos, por meio da análise dos dados, apresentar subsídios que possibilitem pensar sobre a hegemonia que orienta o modelo de educação proposto aos camponeses e vislumbrar o rompimento com os padrões de universalidade das práticas pedagógicas, estabelecer relações entre o sistema social mais amplo e a problematização de questões relacionadas à reprodução social e às desigualdades no âmbito educacional.

Partimos do pressuposto de que a pesquisa inicia com uma relação dinâmica entre a realidade, o pesquisador e o partícipe, sendo possível estabelecer um diálogo holístico que envolve o objeto de estudo em suas amplas dimensões, sendo o ambiente natural uma fonte direta na construção dos 


\section{Universidade do Extremo Sul Catarinense \\ Revista Ibero-Americana de Humanidades, Ciências e \\ Educação \\ UnesC Produção e democratização do conhecimento na lbero-América}

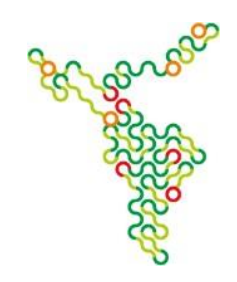

dados. Com fundamento nessa compreensão, buscamos dados que nos possibilitaram apreender o cenário natural e as relações sociais dos partícipes que nele estão inseridos como um todo, conhecendo suas experiências, seus valores, seus princípios, sua cultura e seus modos de contar as suas vivências nas inter-relações com o meio social. Todas essas vertentes foram consideradas neste estudo para a análise dos dados sobre a formação de professores da Educação do Campo (COSTA, 2017), na relação com o estudo de caso etnográfico, destacando para este trabalho as práticas pedagógicas.

A Escola Família Agrícola (EFA) Soinho é instituição de referência em educação, que objetiva atender às concepções de Educação do Campo, no Piauí e até no Brasil, por desenvolver um ensino pautado no cotidiano dos camponeses. A EFA trabalha com a Pedagogia da Alternância (PA), que possibilita ao aluno uma educação que vislumbra a formação integral do ser humano, alternando tempo escolar e tempo comunidade.

Essa especificidade a caracteriza como um caso particular, com singularidades em suas práticas pedagógicas no âmbito do processo de ensino e aprendizagem, de modo que merece um estudo para compreendermos tal particularidade. Esse diferencial nos motivou à opção metodológica pela perspectiva da pesquisa etnográfica - estudo de caso etnográfico -, no qual o pesquisador interage com os partícipes, com um contato direto no espaço da pesquisa, dazendo uma descrição cultural dos povos em suas várias manifestações, revelando costumes, crenças e tradições de uma sociedade, grupo e/ou comunidade, em que os seres humanos são apreendidos como construtores sociais e históricos por meio da cultura que revela modos de vida.

Para André (2008), o estudo de caso etnográfico se tornou importante referencial teórico nas pesquisas que envolvem o cotidiano do processo educativo, por realizar uma descrição densa e por permitir adentrar no campo da pesquisa e observar as nuances das múltiplas relações que entrelaçam o modo de se ver e de se sentir a realidade das pessoas envolvidas no estudo de um caso específico.

O estudo de caso etnográfico possibilitou a compreensão mais detalhada do fenômeno em estudo, visto que o pesquisador se encontra no ambiente no qual acontecem os fatos. Para André (2008), as vantagens de um estudo de caso etnográfico são a possibilidade de se fornecer uma visão profunda, ampla e integrada de um fenômeno; a capacidade de se retratar situações da vida real, sem prejuízos de sua complexidade; e o potencial de contribuição aos problemas da prática educacional. 


\section{Universidade do Extremo Sul Catarinense \\ Revista Ibero-Americana de Humanidades, Ciências e \\ Educação \\ Unesc Produção e democratização do conhecimento na lbero-América}

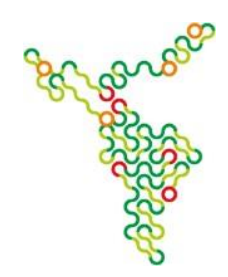

Dessa forma, ao adentrar no campo da pesquisa, tivemos a preocupação de fazer uma análise do objeto de estudo. Na realização da pesquisa, permanecemos na EFA Soinho pelo período de um ano e meio (junho de 2015 a dezembro de 2016), tempo necessário para sistematizar os dados que respondem ao problema de estudo. Vale ressaltar que esses dados foram construídos a contar das experiências observadas por meio dos instrumentos: da observação participante e também por meio do questionário perfil, da escrita do memorial e da realização da entrevista semiestruturada, considerando as múltiplas relações nas quais os partícipes estão imersos.

Neste trabalho, os dados analisados e descritos se referem à observação participante registrada no diário de campo sobre o desenvolvimento da prática pedagógica. Isso possibilitou uma descrição detalhada das vivências dos professores da Educação do Campo no desenvolvimento das práticas pedagógicas observadas pela pesquisadora a partir de um estudo de caso etnográfico como opção metodológica.

\section{Dispositivos da pesquisa: instrumentos de construção dos dados}

Os instrumentos são importantes para a construção dos dados. E, para esta pesquisa, selecionamos os seguintes: observação participante com o uso do diário de campo, memorial de formação e entrevista semiestruturada. Por meio destes, buscamos conhecer aspectos relacionados à formação de professores da Educação do Campo na produção e na valorização dos saberes da cultura camponesa na prática pedagógica (COSTA, 2017), vislumbrando o respeito à diversidade sociocultural.

Iniciamos a construção dos dados pela observação participante, a qual se desenvolveu durante o período em que estivemos na EFA. Na sequência, apresentamos o memorial, conversamos individualmente com cada um sobre a escrita desse documento para a construção dos dados e combinamos uma data para que ele fosse entregue. Neste trabalho, as análises apresentadas são com base na observação participante, tendo o diário de campo como recurso para registrar as observações mediante as interações sociais entre pesquisador e participantes.

Angrosino (2009) define a observação como um ato de perceber um fenômeno e registrá-lo com propósito científico, descrevendo as atividades e as inter-relações dos sujeitos em seu contexto por meio dos sentidos do pesquisador, exigindo registro objetivo para que os dados sejam 


\section{Universidade do Extremo Sul Catarinense \\ Revista Ibero-Americana de Humanidades, Ciências e \\ Educação \\ Unesc Produção e democratização do conhecimento na lbero-América}

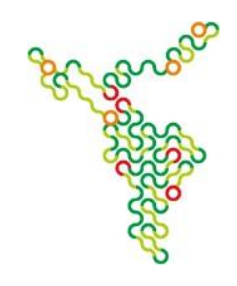

sistematizados de forma detalhada e holística. Segundo André (1995, p. 28), “[...] a observação é chamada de participante porque parte do princípio de que o pesquisador tem sempre um grau de interação com a situação estudada, afetando-a e sendo por ela afetado.”.

Utilizamos o diário de campo durante a observação participante, no período em que estivemos no locus da pesquisa. Esse instrumento, segundo Macedo (2010), é uma técnica para a construção dos dados que se trata, em geral, de um aprofundamento reflexível sobre as experiências vividas no espaço da pesquisa e no campo de sua própria elaboração intelectual.

Esse recurso visa apreender de forma profunda e pertinente o contexto do trabalho de investigação científica e se imbrica no próprio objeto, permitindo que nos situemos melhor em torno de suas nuances, além de possibilitar ao pesquisador escrever sobre as diversas relações sociais que envolvem o objeto estudado, fazendo uma descrição densa e uma análise crítico-reflexiva entre o visível e o dizível.

Para Matos (2011), a observação participante se constitui em um instrumento relevante nas pesquisas que trabalham com estudos etnográficos, pois coloca o participante como protagonista da pesquisa, possibilita a imersão na cultura local por um tempo, se tornado um membro. Assim, foi possível fazer uma descrição do contexto da Escola em relação ao desenvolvimento da prática pedagógica de professores da Educação do Campo.

Participamos de várias atividades, tais como: reuniões, culminância de projetos da Escola, Formação Inicial para Monitores (professores) em Pedagogia da Alternância (PA), semana pedagógica, socializações de Plano de Estudo, aulas práticas de campo e atividades em sala de aula, comemorações festivas, dentre outras. Nessas práticas observadas, estávamos fazendo o registro constante dos dados, o que nos possibilitou compreender a dinâmica da EFA, a articulação dos saberes da cultura camponesa no que se refere às tradições da comunidade e à sua economia.

Percebemos, por meio da observação participante - com o registro no diário de campo, e dos diálogos que mantivemos com os professores, com a equipe gestora e os alunos - que as atividades práticas do curso são voltadas para a agricultura familiar, para a sustentabilidade, para a promoção do desenvolvimento do aluno em sua comunidade, conforme é proposto o ensino nas EFAs com a metodologia da PA. O que implica em uma relação entre a vida cotidiana dos camponeses e a escola, 


\section{Universidade do Extremo Sul Catarinense \\ Revista lbero-Americana de Humanidades, Ciências e \\ Educação \\ Unesc Produção e democratização do conhecimento na lbero-América}

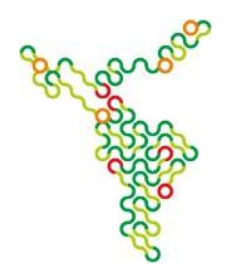

“[...] sai da experiência no encontro de saberes mais teóricos para voltar novamente à experiência e assim sucessivamente.” (GIMONET, 2007, p. 29).

$\mathrm{Na}$ observação participante constatamos esse movimento no encontro de saberes por meio da diversidade das práticas pedagógicas, que possibilitam ao aluno fazer essa articulação dos seus saberes culturais com os saberes escolares. Ao descreverem suas práticas os professores da EFA Soinho dissertam sobre o cotidiano dos camponeses e a importância de considerá-lo. O tópico que seguem trazem as contribuições da pesquisa sobre as práticas pedagógicas mediante o estudo de caso etnográfico.

\section{Estudo de caso etnográfico e as práticas pedagógicas: contribuições pela pesquisa}

A pesquisa desenvolvida possibilitou captar as imagens/impressões do campo de estudo e fazer as interpretações. Por centrar nos fenômenos sociais e culturais das dinâmicas das práticas pedagógicas, decidimos pela nomenclatura prática pedagógica, que se dá pela compreensão, segundo Franco (2016, p. 536), no sentido de práxis, “[...] como uma ação consciente e participativa, que emerge da multidimensionalidade que cerca o ato educativo". Tem a finalidade, segundo a autora, de concretizar processos pedagógicos. Assim esses processos não acontecem em um vazio conceitual, mas que culminam em bases teóricas, em conhecimentos acadêmicos, os quais não podem deixar de considerar os conhecimentos construídos por meio de vivências sociais e culturais.

Partindo dessa compreensão de prática pedagógica, o estudo de caso etnográfico oportunizou fazer uma análise interpretativa e crítica, no contexto organizacional da escola, sobre a concretização desses processos pedagógicos. A Escola Família Agrícola do Soinho (EFA - SOINHO), como é conhecida, destaca-se no Piauí pela sua proposta de ensino, pelas práticas pedagógicas, pois busca atender aos princípios da Educação do Campo, por sua metodologia e por seus trabalhos desenvolvidos.

A proposta teórica e metodológica da Pedagogia da Alternância (PA), aprovada pelo Parecer n. 1 de fevereiro de 2006 (BRASIL, 2006) do Conselho Nacional de Educação, na EFA possibilita ao aluno articular o ensino com as suas raízes na comunidade, valorizando e respeitando a diversidade sociocultural dos povos do campo, bem como relacionando teoria e prática no processo de ensino e 


\section{Universidade do Extremo Sul Catarinense \\ Revista Ibero-Americana de Humanidades, Ciências e \\ Educação \\ Unesc Produção e democratização do conhecimento na lbero-América}

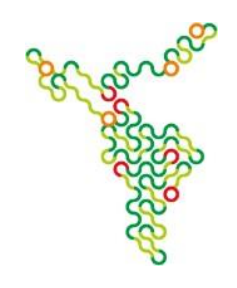

aprendizagem. O que a caracteriza como um caso singular, específico e diferenciado entre as demais escolas agrícolas, tornando-a referência. Esses elementos que a distingue contribuíram para o desenvolvimento desse estudo.

Vale ressaltar que as EFAs com a PA no Brasil, inclusive no Piauí, consolidaram-se por acreditar "[...] no homem do campo e na possibilidade de promover uma educação diferente que resgata o valor da terra, que une formação técnica profissional à formação humanística e que torna o agricultor familiar auto-sustentável”. (JESUS, 2011, p. 67). Nas práticas pedagógicas desenvolvidas, por meio da PA nesse contexto de educação, difere-se em metodologias e conteúdos da educação propostos no ensino regular, promove-se uma educação que possibilita ao aluno fortalecer a sua cultura e os seus vínculos familiares e comunitários na perspectiva de uma formação integral da pessoa.

Isso porque o objetivo das EFAs, segundo Gimonet (1999, 2007), é de promover e desenvolver o espaço do campo, por meio da Educação do Campo, que visa à formação do ser humano como um todo para a promoção do desenvolvimento, criando condições de vida digna, levando em consideração as perspectivas socioeconômicas apresentadas pelas atividades agropecuárias de transformação e pelos serviços existentes nesse contexto, bem como possibilitando o acesso a outras atividades profissionais.

A Pedagogia da Alternância, ao alternar tempo escola e tempo comunidade, se desenvolve na perspectiva, de resgatar o valor da terra, do camponês, de seus valores e princípios, uma metodologia específica, diferenciada, que faz uso de instrumentos e/ou mediações didático - pedagógicas (GIMONET, 1999, 2007; JESUS, 2011) que possibilitam aos professores explorar, nas práticas pedagógicas, temáticas que buscam dar respostas, por meio de problematizações que levam a reflexões sobre as condições de vida, às necessidades dos camponeses.

Com o diário de campo em mãos, dávamos, então, início aos trabalhos de construção dos dados, fazendo visitas periódicas participando de várias atividades, dentre elas: reuniões pedagógicas, socialização do plano de estudo, acompanhamento nas atividades de campo, dentre outras. Uma das primeiras atividades que participamos em sala de aula foi a socialização do Plano de Estudo (PE), que acontece no primeiro dia de cada sessão. O PE, de acordo com Jesus (2011), constitui um meio para o diálogo entre aluno-EFA-família, aproximando os saberes científicos e populares. Os alunos,

Revista Ibero-Americana de Humanidades, Ciências e Educação. Criciúma, v.5. n.3, 2019.

Criciúma, 2018, ISSN - 2446-547X 


\section{Universidade do Extremo Sul Catarinense \\ Revista Ibero-Americana de Humanidades, Ciências e \\ Educação \\ Unesc Produção e democratização do conhecimento na lbero-América}

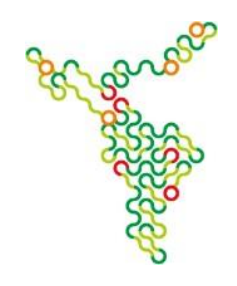

ao término da sessão escolar, são orientados a realizar uma pesquisa na sua comunidade durante a sessão familiar, fazendo uso de entrevistas para amealhar dados sobre determinada temática. Ao retornar, apresentam os resultados.

Os temas são vários, desde os enfoques familiares aos econômicos, e tal atividade revela modos de vida, de produção, de crenças das comunidades dos alunos, o que compreendemos que possibilita ao professor conhecer os camponeses em suas especificidades socioculturais, bem como oportuniza construir dados sobre os saberes da sua cultura. Esses temas servem de base para os professores definirem conteúdos e práticas pedagógicas, buscando desenvolver um ensino que articula saber popular e saber escolar a partir da realidade dos camponeses. Vale ressaltar que para apoiar as práticas em sala de aula, são realizadas intervenções - atividades que buscam apreender melhor as temáticas estudadas -, que acontecem por meio de palestras e de aulas práticas em outras instituições.

Também acompanhamos os professores em várias atividades de campo, tais como: medição de terrenos para a implantação de módulos produtivos, preparo de mudas, poda de plantas, limpeza de módulos, dentre outras atividades que são chamadas na EFA de circuito produtivo. Nessas tarefas, observamos que o diálogo entre professor e aluno se constituía em uma partilha de conhecimentos. Além dessas práticas de campo, acompanhamos os professores nas ações em sala de aula e também em atividades de estudo.

Durante esse ano e meio em que estivemos participando das atividades no locus da pesquisa, foi possível compreender a dinâmica de funcionamento da EFA. Ao participarmos dessas atividades, compreendemos "[...] que falar de prática pedagógica é falar de uma concepção de pedagogia [...]" (FRANCO, 2016, p. 540), de como essa se relaciona com a prática docente e com a intencionalidade de um projeto educativo que postula um ensino articulado com o cotidiano dos camponeses.

Juntamente com outros instrumentos, a observação participante nos estudos etnográficos possibilita ao pesquisador participar como membro do grupo, Matos (2011) afirma ser possível por meio desse instrumento o desenvolvimento de análises indutivas, análise de contexto, análise de discurso, análise cultural, análise critica dentre outras. O que possibilitou durante o tempo em que estivemos no locus da pesquisa, fazer análises da cultura, do contexto em que se insere as práticas pedagógicas. 


\section{Universidade do Extremo Sul Catarinense \\ Revista Ibero-Americana de Humanidades, Ciências e \\ Educação \\ Unesc Produção e democratização do conhecimento na lbero-América}

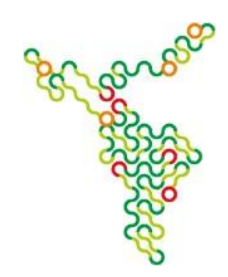

Na EFA Soinho a rotina das práticas pedagógicas, no contexto da escola, e da prática docente (no espaço da sala de aula) é bem dinâmica. Diariamente, os alunos têm aulas práticas de campo, paralelas às atividades de sala de aula. Também há intervenções externas, como palestras sobre os temas que estão sendo estudados e visitas de estudo em outras instituições, como uma forma de aprofundamentos dos conteúdos.

Mediante esta dinamicidade, podemos afirmar conforme Franco (2016, p. 540) que “[...] a prática pedagógica docente está profundamente relacionada aos aspectos multidimensionais da realidade local e especifica, às subjetividades e à construção histórica dos sujeitos individuais e coletivos". As práticas pedagógicas no âmbito da EFA Soinho, trazem uma intencionalidade, uma sistematização e uma contextualização para promover um ensino pautado no protagonismo dos camponeses.

A partir de um ensino contextualizado, “[...] nosso propósito é conceber uma Educação do Campo, voltada aos interesses e ao desenvolvimento sociocultural e econômico dos povos que habitam e trabalham no campo, atendendo às suas diferenças históricas e culturais" (FERNANDES; CERIOLI; CALDART, 2009, p. 27). Faz-se necessário e urgente pensar a educação inserida em um contexto, pautada na formação do ser humano como um todo, no respeito à diversidade sociocultural e à dignidade humana, que inclua essa perspectiva de ensino a todos como direito.

Essa dinamicidade e contextualização do ensino, se dá pela diversidade de instrumentos que os professores fazem uso nas práticas pedagógicas. Esses instrumentos estão presentes nas atividades desenvolvidas pela equipe gestora, professores e alunos. O Quadro 1, a seguir, apresenta a síntese, elencando cada instrumento e a finalidade, construído com base na observação participante e nos estudos de Jesus (2011), Gimonet, (1999, 2007) e do Parecer (BRASIL, 2006).

\section{Quadro 1 - Síntese dos Instrumentos das EFA}

\begin{tabular}{|l|l|l|}
\hline Classificação & Instrumentos & \multicolumn{1}{c|}{ Finalidade da atividade na EFA } \\
\hline $\begin{array}{l}\text { Instrumentos } \\
\text { de pesquisa }\end{array}$ & Plano de Estudo & Pesquisa da realidade da comunidade dos alunos \\
\cline { 2 - 3 } & Estágios & $\begin{array}{l}\text { Vivência no âmbito profissional com escrita apresentação de } \\
\text { relatórios }\end{array}$ \\
\hline
\end{tabular}




\section{Universidade do Extremo Sul Catarinense \\ Revista lbero-Americana de Humanidades, Ciências e \\ Educação \\ Unesc Produção e democratização do conhecimento na lbero-Améríca}

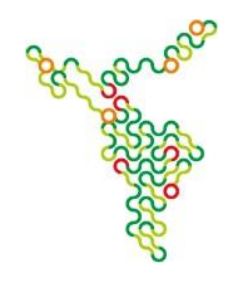

\begin{tabular}{|l|l|l|}
\hline \multirow{4}{*}{$\begin{array}{l}\text { Instrumentos } \\
\text { comunicação/ } \\
\text { relação }\end{array}$} & Colocação em Comum & Apresentação e discussão dos resultados da pesquisa do PE \\
\cline { 2 - 3 } & Tutoria & Acompanhamento personalizado ao aluno \\
\cline { 2 - 3 } & Caderno da Realidade & Registro das vivências na sessão familiar e escolar \\
\cline { 2 - 3 } & Visitas às Famílias & $\begin{array}{l}\text { Acompanhamento do desenvolvimento do aluno no meio } \\
\text { socioprofissional e familiar }\end{array}$ \\
\hline \multirow{4}{*}{$\begin{array}{l}\text { Instrumentos } \\
\text { didáticos }\end{array}$} & Visitas de Estudo & Viagem para locais que objetivam um aprofundamento do PE \\
\cline { 2 - 3 } & Intervenções Externas & $\begin{array}{l}\text { Atividades livres de integração realizadas à noite pelos alunos e } \\
\text { professor do plantão }\end{array}$ \\
\cline { 2 - 3 } & $\begin{array}{l}\text { Atividades realizadas por pessoas de fora da Escola para aprofundar } \\
\text { as temáticas dos PEs }\end{array}$ \\
\cline { 2 - 3 } & Projeto Profissional & $\begin{array}{l}\text { Construção e apresentação/defesa de um projeto para a execução de } \\
\text { um módulo produtivo }\end{array}$ \\
\cline { 2 - 3 } & Avaliação Formativa & $\begin{array}{l}\text { Processo contínuo baseado nos instrumentos da PA, vendo o } \\
\text { desenvolvimento do aluno como um todo }\end{array}$ \\
\hline
\end{tabular}

Fonte: Dados construídos com base nas teorias e nos dispositivos empíricos da pesquisa

O desenvolvimento da prática pedagógica com esses instrumentos possibilita relacionar com a teoria e vice-versa, também conhecimento científico e empírico, saber acadêmico e popular, na perspectiva da unidade teoria-prática para estabelecer relações entre a escola e a comunidade.

A observação participante nos possibilitou fazer uma análise interpretativa das práticas pedagógicas da EFA Soinho, compreendemos a importância de uma educação contextualizada, articulada às experiências dos alunos. Segundo Sousa, Melo e Rodrigues (2016), a prática pedagógica deve se tornar uma prática social dialógica, consolidando-se como uma ação política concreta, em que se constroem conhecimentos, refletindo em transformações no desenvolvimento do ser humano.

Esse modelo de educação que considera a diversidade cultural dos camponeses se constitui no ideário da Educação do Campo defendido pelos seus idealizadores, na perspectiva de uma escola que “[...] trabalha os interesses, a política, a cultura e a economia" (FERNANDES, CERIOLI, CALDART, 2009) dos camponeses e de uma educação que, “[...] por querer enfrentar, confrontar e derrotar a escola capitalista, não se deixa enredar pelos muros da Escola e muito menos, pelas quatro paredes da sala de aula” (MOLINA; SÁ, 2012, p. 330), desenvolvendo outros modelos de pedagogias a partir do protagonismo dos sujeitos do campo (ARROYO, 2012). 


\section{Universidade do Extremo Sul Catarinense \\ Revista lbero-Americana de Humanidades, Ciências e \\ Educação \\ Unesc Produção e democratização do conhecimento na lbero-América}

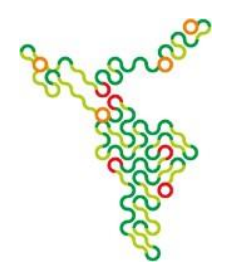

Essas perspectivas educativas são confirmadas na EFA Soinho quando são desenvolvidas, por meio da PA, várias práticas pedagógicas que vão do ambiente da sala de aula ao contexto das famílias em suas comunidades, vislumbrando uma formação integral do ser humano. Ao trabalhar conteúdos com fundamento na realidade dos camponeses possibilita maior interação e aprendizagem significativa, bem como a formação como um todo. Esse modelo de educação protagonizado pelas EFAs revelou-se como um dispositivo, hoje com amparo legal, em modalidade de educação que fez e faz nascer a esperança de uma educação para todos.

\section{Considerações finais}

O estudo nos revelou a importância da pesquisa com os estudos etnográficos para compreensão das práticas pedagógicas. Nessa relação metodologia e objeto de estudo, vemos emergir as contribuições da pesquisa com o estudo de caso etnográfico. A análise traz aspectos que fazem da prática pedagógica de professores da Educação do Campo um espaço de diálogo entre saberes, de valorização da cultura, de promoção de uma educação pautada no cotidiano dos camponeses.

Essa compreensão e interpretação se devem, ao um estudo orientado pelas vivências dos pesquisados em seu contexto natural, no qual o pesquisador esteve inserido, como um participante. Com a observação participante foi possível descrever de forma densa a dinâmica do cotidiano da prática pedagógica na EFA Soinho. O que implicou em conhecimento sobre os diversos saberes dos camponeses que são mobilizados na prática e como se articulam aos saberes escolares.

A partir das análises, aprendemos que os professores da Educação do Campo, no desenvolvimento da prática pedagógica alicerçada na cultura dos camponeses, indicam mecanismos que contribuem para a produção de saberes como uma construção sociocultural. Essa prática é tecida pelas relações sociais entre os sujeitos envolvidos no processo de ensino e aprendizagem ao relacionar saber popular e saber científico, trazendo outras pedagogias para outros sujeitos (ARROYO, 2012). Entendemos que este modelo de educação proposto na EFA, ao utilizar a metodologia orientada pela PA, busca a formação do ser humano como um todo e fortalece a sua identidade sociocultural.

\section{Referências}

ARROYO, M. G. Outros sujeitos, outras pedagogias. Petrópolis, RJ: Vozes, 2012. 


\section{Universidade do Extremo Sul Catarinense \\ Revista lbero-Americana de Humanidades, Ciências e \\ Educação \\ Unesc Produção e democratização do conhecimento na lbero-América}

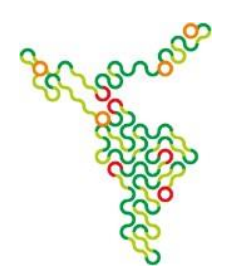

ANDRÉ, M. E. D. A. Estudo de caso em pesquisa e avaliação educacional. 3. ed. Brasília: Liber, 2008.

. Etnografia da prática escolar. Campinas, São Paulo: Papirus, 1995.

ANGROSINO, M. Etnografia e observação participante. Porto Alegre: Artmed, 2009.

BRASIL. Constituição da República Federativa do Brasil. Brasília, DF: Senado Federal: Centro Gráfico, 1988.

Parecer CNE/CEB, n. 1/2006. Dias letivos para a aplicação da Pedagogia de Alternância nos Centros Familiares de Formação por Alternância (CEFFA). Disponível em: <http://portal.mec.gov.br/cne/arquivos/pdf/pceb001_06.pdf>. Acesso em: 27 dez. 2016.

COSTA. M. L. da. Professores da Educação do Campo: dos percursos formativos aos saberes da cultura camponesa na prática pedagógica. 2017. 261f. Tese (Doutorado em educação) - Programa de Pós-Graduação em educação, Centro de Ciências da educação, Universidade Federal do Piauí, Teresina, 2017.

FERNADES, B. M.; CERIOLI, P. R.; CALDART, R. S. Primeira Conferência Nacional "Por uma educação básica do campo". In: ARROYO, M. G.; CALDART, R. S.; MOLINA, M. C. (Org.). Por uma educação do campo. Petrópolis, RJ: Vozes, 2009. p. 19-64.

FRANCO, M. A. R. S Prática pedagógica e docência: um olhar a partir da epistemologia do conceito. Rev. bras. Estudos. Pedagógicos. (on-line), Brasília, v 97, n. 247, p. 534-551, set./dez. 2016. Disponível em: HTTP//dx.doi.org/10.1590/s2176-6681/288236353. Acesso em: 27set. 2017.

GIMONET, J. C. Nascimento e desenvolvimento de um movimento educativo: as casas familiares rurais de educação e orientação. In: Seminário Internacional da Pedagogia da Alternância: Alternância e Desenvolvimento, 1999. Anais... Salvador: UNEFAB, 1999, p. 39-48.

. Praticar e compreender a pedagogia da alternância dos CEFAs. Tradução de Thierry de Burghgrave. Petrópolis, RJ: Vozes; Paris, FR: Associação Internacional dos Movimentos Familiares de Formação Rural - AIMFR, 2007.

JESUS, J. G. Formação de professores na pedagogia da alternância: saberes e fazeres do campo. Vitória, ES: GM, 2011.

MACEDO, R. S. Etnopesquisa crítica, etnopesquisa-formação. 2. ed. Brasília: Liber, 2010.

MATOS, C. L. G. Estudos etnográficos da educação: uma revisão de tendências no Brasil. In: .; CASTRO, P. A. (Org.). Etnografia e educação: conceitos e usos. Campina Grande:

EDUEPB, 2011. p. 25-50. Disponível em: <http://books.scielo.org>. Acesso em: 09 set. 2017.

MOLINA, M. C.; SÁ, L. M. Desafios e perspectivas na formação de educadores: reflexões a partir da licenciatura em Educação do Campo da universidade de Brasília. In: XV Encontro nacional de

Revista Ibero-Americana de Humanidades, Ciências e Educação. Criciúma, v.5. n.3, 2019. 
didática e prática de ensino, 2010, Belo Horizonte. Anais... Convergências e tensões no campo da formação e do trabalho docente. Belo Horizonte: Autêntica, 2012. p. 369-388.

SOUSA, A. P. F.; MELLO, R. M. V.; RODRIGUES, J. A. Práticas pedagógicas: interações, desafios e possibilidades no cotidiano de uma Escola Família Agrícola. Revista Brasileira educação campo, Tocantinópolis, v. 1, n. 2, p. 402-427, fev. 2016. 